\title{
Reading with new tools: an evaluation of Personal Digital Assistants as tools for reading course materials
}

\author{
Jenny Waycott \\ Institute of Educational Technology, The Open University \\ email:J.L.Waycott@open.ac.uk
}

Lightweight, palmtop devices such as personal digital assistants (PDAs) can now be used for reading electronic text, opening up their potential as learning tools. This paper reports a study that evaluated the use of PDAs for reading course materials by students on an Open University master's course. The research is grounded in activity theory, which provides a useful framework for examining how the introduction of a new tool changes an existing activity. Student perceptions of the possibilities and constraints of the PDA, as determined by questionnaires and interviews, reveal the impact the new tool had upon reading. The PDA constrained reading with limitations such as the small screen size, new requirements for navigating through the text and awkward methods for taking notes. These conditions made it difficult for students to skim-read the text, to move back and forth within the document and to interact with the text as easily as they could with paper. Nevertheless, students welcomed the opportunity to have the course materials on a portable, lightweight device that could be used at any time and in any place. This made it easier to fit the reading activity around the various other activities in which students were involved. In addition, the PDA was used in conjunction with existing tools, such as the printed version of the course materials and the desktop computer. Therefore, it was not seen to replace paper but rather to extend and complement it. The findings are discussed using concepts from activity theory to interpret how the new tool modified the reading activity.

\section{Introduction}

Eleven years ago, Tom Stonier predicted that personal computers would soon be 'pocketbook sized and contain a wide range of features and capabilities', which would become 'the ultimate in electronic books' (Stonier, 1991: 364). Today, it appears that Stonier's prediction has come true. People now have access to highly personal, portable computers, such as palmtop computers or personal digital assistants (PDAs), which can be used for 
various functions, including supporting time and information management, recording and storing notes, and accessing Internet content. Furthermore, the availability of e-book reading software for many PDAs means that they can now also be used to read electronic documents, opening up more possibilities for their potential as learning tools. Several authors have argued that PDAs and similar devices could be usefully exploited in educational contexts (Fung, Hennessy and O'Shea, 1998; Hennessy, 2000; Sharples, 2000; Soloway, Hennessy and O'Shea, 2001). Sharples (2000), for example, proposes that palmtop computers could be valuable lifelong learning tools, used to input data or access information whenever it is needed. Portable devices could also be useful for distance education students, who typically have to fit their self-managed learning activities around other tasks, such as work and family commitments (Jones, Kirkup and Kirkwood, 1992). Providing access to learning resources anytime and anywhere, PDAs could enable students to make more effective use of time while away from the home or office environment.

Using PDAs, however, would also impose some limitations. As Carroll and colleagues argue, the possibilities and constraints introduced by a new tool will change the activity that the tool is used to support, a process they term the 'task-artifact cycle': 'an artifact suggests possibilities and introduces constraints that often radically redefine the task for which the artifact was originally developed' (Carroll, Kellogg and Rosson, 1991: 79). The primary possibility introduced by a PDA is, of course, portability and, consequently, the ability to have easy access to information stored electronically. The constraints are equally apparent. The portability of the PDA compromises other features such as screen size, which has to be small enough for the device to fit in the palm of the hand. As Dillon (1994) argues, a small screen isolates the text on display, removing it from its context and making it difficult to scan-read. Furthermore, PDAs do not benefit from the same data input capabilities as desktop and laptop computers, which typically have a full-size keyboard and mouse. Most PDAs have touch-sensitive screens that enable direct manipulation of the onscreen interface through the touch of a stylus or finger. While such an interface is useful for quickly accessing and viewing applications, it is not so beneficial for entering text. Typically, users would enter text on a PDA using a small on-screen keyboard or by writing on the screen in a special handwriting script, which the PDA then converts into type. Handwriting recognition systems, however, lack speed and accuracy, and data input methods on PDAs are generally considered problematic (Pascoe, Ryan and Morse, 2000).

The purpose of the research reported in this paper is to elucidate how the possibilities and constraints introduced by a PDA change the activity of reading course materials in a distance education context, as determined by students' perceptions of this experience. The research is grounded in activity theory, which provides a useful means for describing how the introduction of a new tool changes an existing activity. The theoretical background of the research is elaborated further below, followed by a description of the study undertaken.

\section{Examining new tool use: activity theory}

Activity theory (Leont'ev, 1978; Vygotsky, 1978) emphasizes the sociocultural context in which activity takes place. One of the central tenets of activity theory is the notion that all human activity is mediated by the use of tools, both conceptual tools such as language, and physical tools such as technology. These tools are one aspect of the sociocultural context of the activity. Engestrom (1996) has extended this notion of tool mediation to provide a representation of the wider social context of activity, as shown in Figure 1. According to 
this model, activity takes place within a community of people who share the same object, or goal, of activity. There is a division of labour among members of the community and this mediates the relationship between the community and the object. In addition, the community is governed by a set of rules, that is, norms and standards that regulate the activity, and these mediate the relationship between the subject and the community (Kuutti, 1996).

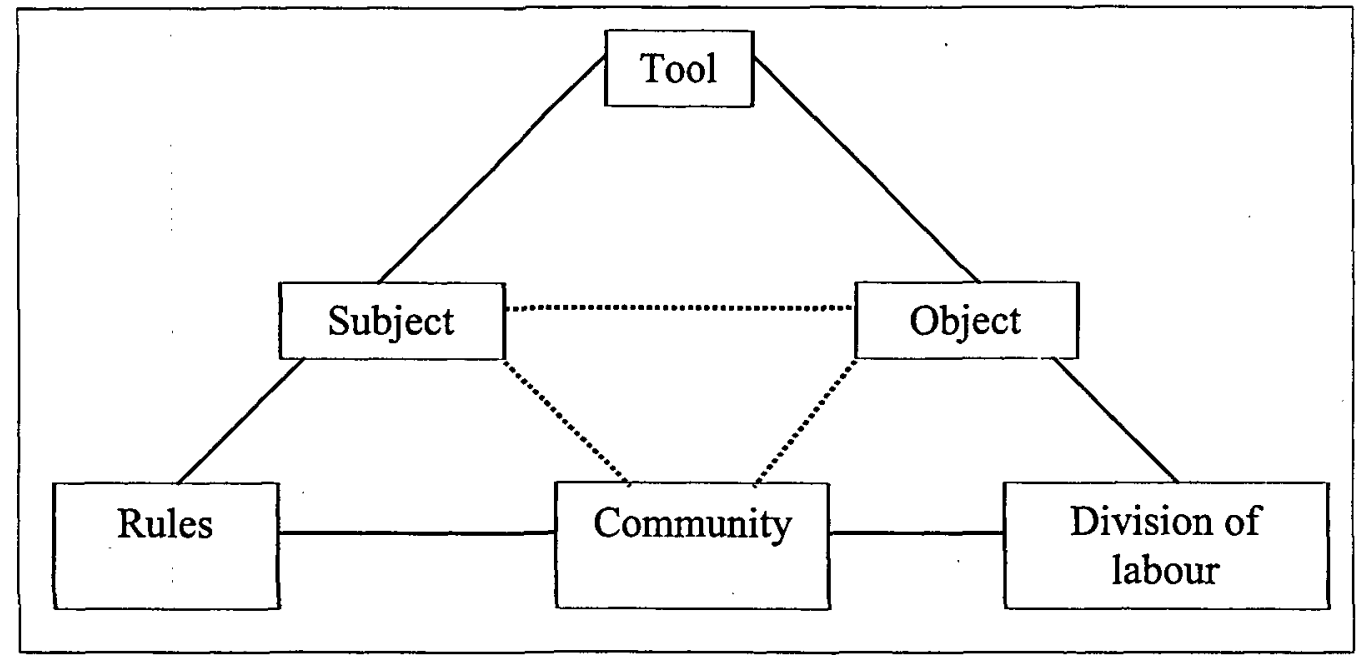

Figure 1: Activity triangle model (from Engestrom, 1996)

The emphasis on the mediational role of tools in activity means that activity theory has gained popularity for use in research examining the impact of new technologies on learning and workplace cultures (for example, Mwanza, 2001; Halloran, Rogers and Scaife, 2002). Activity theory also provides tools for understanding the impact of new technologies at the operational level of activity. Leont'ev (1979) divided activity into hierarchical layers, consisting of actions and operations. Operations are routinized processes that are carried out to perform the action. The action is a conscious process with a specific goal that helps to meet the overall objective of the activity. For example, the activity of reading with the objective of learning might consist of such actions as reading specific course texts, taking notes, looking up cited texts, discussing the course materials with other students, and so on. The operations through which these actions are performed would include turning pages in the document, using a pen and paper to take notes, and flicking through the document to move back and forth between sections.

The actions and operations that contribute to an activity will change as the activity evolves. Actions may become routinized over time and consequently be transformed into operations. Meanwhile, if the conditions of the activity change, an operation may become an action, requiring conscious effort directed at a specific goal (Kuutti, 1996). The introduction of a new mediating tool - such as a new computer program - would change the conditions of the activity. Processes that were formerly operations - when a more familiar tool was used - would become individual actions, and over time, as familiarity with the new tool increases, these actions may become operationalized (Bodker, 1991). The 
introduction of a new tool such as a PDA, then, would change the relationship between the actions and operations that contribute to the activity of reading.

\section{Reading mediated through computer tools}

Past research has examined how the use of new computer tools impacts upon reading. For example, Dillon (1994) reviewed early research that compared reading from a computer screen with reading from paper. He concluded that familiarity with paper materials, and the presence of contextual clues such as paper size and document weight, means readers are generally more efficient at navigating through paper documents than electronic text. Similarly, O'Hara and Sellen (1997) compared the two media and found that paper offered several advantages over computers. Participants in their study were assigned to either an 'online' condition or a 'paper' condition, and were given a four-page article to read and summarize. Those in the paper condition were able to navigate efficiently through the document, using their familiarity with the page layout to flick through the pages, simultaneously recording notes on separate paper. In other words, these processes were operationalized. Meanwhile, those using the electronic version found it cumbersome to switch between viewing the document and taking notes (which was also done on the computer), and they were only able to perform these actions serially, rather than simultaneously. Thus, using the new tool constrained the activity of reading by introducing new conditions for the activity, which made it difficult for participants to utilize the operations they had developed from past experience with paper documents.

It is to be expected, therefore, that a new tool such as a PDA would create new conditions for the reading activity which may inhibit the use of operations previously developed and require new time-intensive actions. The study described below aimed to identify such changes, as well as to examine the impact of the PDA on the wider social context of the activity.

\section{The study}

\section{The study context}

The study centred on the UK Open University course Applications of Information Technology in Open and Distance Education', one of three courses that make up a master's programme in open and distance education. Students are encouraged to critique and evaluate their own experiences of using information technology on the course. For this reason, the course provided a valuable forum in which to conduct this study, as students were generally eager to try out a new medium for reading course materials, and interviewees and questionnaire respondents offered extensive feedback on their experience of using the PDA for reading.

The course is undertaken part-time and students are involved in various other professional activities. All 65 students enrolled in the course were supplied with Palm m105 PDAs at the end of July 2001. However, participation in the evaluation of PDAs was voluntary. Students on this course were primarily novice PDA users, although nine students said they already owned a PDA or had used palmtop computers in the past.

The course is primarily delivered online, making use of Web resources and FirstClass conferencing software. However, during the final block of the course, students use printbased reading materials, and it was during this block that the study was conducted. Three 
sections of the study guide used during this block were provided for access through the PDA (67 A4 pages). These sections make up nearly half of the study guide, which is a discursive guide to the readings for the block, written by academics associated with the course. During the study, students had access to both the printed version of the study guide and the electronic version on the PDA. The remaining sections of the study guide and other reading materials were provided on paper only. The documents on the PDA were entirely text-based and were supplied as Word documents, not reformatted for presentation on the PDA. The default font size of the text was 12 points (this could be changed by the user). An example screen view of the text on the PDA is shown in Figure 2.

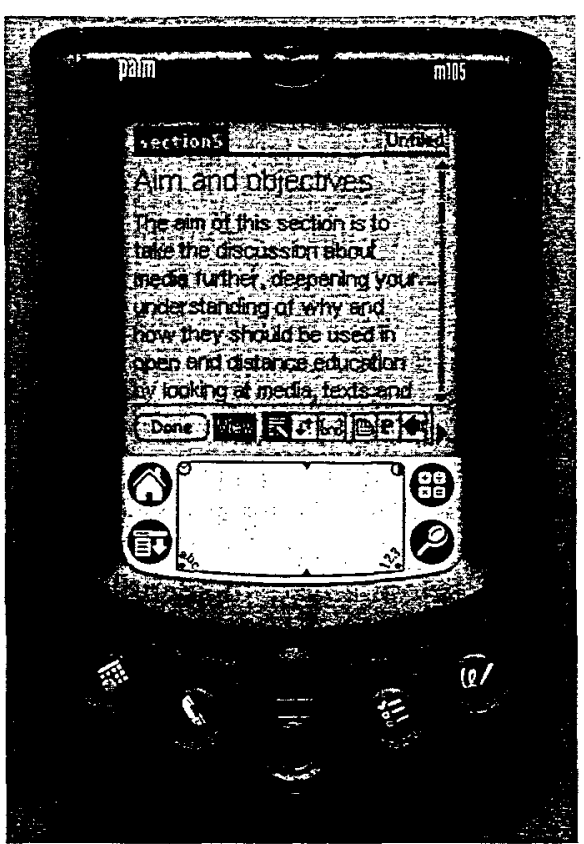

Figure 2: An example screen view of the study guide on the PDA

\section{Equipment}

\section{$P D A s$}

The Palm m105 is a relatively affordable model that offers typical PDA features, such as note-taking facilities, an address book, calendar and to-do list. It has $8 \mathrm{mb}$ of Random Access Memory, sufficient for storing a large amount of electronic text. It has a touchsensitive screen and text can be entered by tapping letters on an onscreen keyboard, or by using the Graffiti handwriting recognition software. This involves learning the specific Graffiti alphabet characters and writing these on the screen with the stylus, which the PDA then converts into type. The Palm m105 is $11.8 \mathrm{~cm} \times 7.9 \mathrm{~cm}$ (screen area is $5 \mathrm{~cm} \times 5 \mathrm{~cm}$ ) and it weighs $125 \mathrm{~g}$ with batteries installed. It operates on two AAA batteries, which should last for up to two months. It has a monochrome display, with black writing on a green background.

\section{Document reader software}

WordSmith, a commercially available document editor and viewer, was used to present course materials on the PDA. This was chosen because it is a flexible program that can be 
used for a variety of purposes, including to record notes, edit documents and read text. Users can move through the text in a variety of ways: by using the scroll bar on the side of the screen; using the buttons at the bottom of the device; or by using the additional scrolling facilities of the software, such as the 'teleprompter' facility which moves the text automatically. The software has search facilities, such as 'Find', which seeks out instances of the specified word, and 'Go to paragraph', which allows users to jump to a particular paragraph.

\section{Instructions}

Students were given the manufacturer instruction manuals for the PDA and WordSmith software, as well as additional instructions developed by the researcher. These included hints about using the PDA for reading course materials - for example, suggestions about how to take notes on the PDA, how to underline or embolden sections of text, and how to use other features of WordSmith, such as the 'Find' and 'Go to paragraph' facilities.

\section{Data collection}

\section{Interviews}

Approximately two months after students received the PDA, telephone interviews were conducted with ten students who were randomly selected from the entire cohort of students on the course. Only a small sample of students could be interviewed due to time constraints. Nevertheless, the interviews elicited in-depth information about the selected students' perceptions of the benefits and limitations imposed by the PDA, and how the PDA changed the reading activity.

\section{Questionnaires}

Online questionnaires were administered at the end of the course; thirty-five responses were received. A mixture of closed and open-ended questions asked students what features of the PDA they had used, whether they had found the PDA to be a useful tool for supporting their studies, the sort of reading strategies they adopted when using the PDA, and what the benefits and limitations were of using the PDA to read course materials. Responses to open-ended questions regarding the latter are reported here. A full report of the findings can be found in Waycott and Kukulska-Hulme (2001).

\section{How the PDA changed reading}

This section identifies students' perceptions of the possibilities and constraints associated with reading from the PDA. The impact of these possibilities and constraints is discussed with reference to concepts from activity theory, particularly with regard to how the PDA changed the relationship between actions and operations and modified the wider social context of the reading activity.

\section{Portability}

When asked what was the main benefit of using the PDA to read course materials, most questionnaire respondents (63 per cent) referred to the portability of the device. Portability also emerged as a common theme in the interviews. Being able to carry around course materials in a small, lightweight device appeared to change the activity of reading. In particular, it made it easier for students to fit their reading around other activities. One interviewee said: 
It was so much easier to do the work, you could do it everywhere and when you're trying to fit it in around work and kids and everything, that was an enormous advantage.

The PDA enabled students to read course materials in various situations, even while they were carrying out other activities. For example, one interviewee said he used the PDA while stuck in traffic. Another interviewee used the PDA to read course materials while in work meetings when the topic being discussed was not relevant to her. The PDA was an 'unobtrusive and neat device that could always be to hand'. Some students used the PDA to aid the process of revision, re-reading course materials when away from the desk or office environment. The possibility of accessing course materials anytime anywhere, then, had the potential to change the way students undertook the reading activity, particularly with regards to how reading course materials was structured around other activities.

\section{Screen display}

Students also identified limitations of using the PDA for reading. In particular, the small screen size and poor screen quality of the PDA caused some constraints. The limited amount of text visible meant that students had to adopt a 'line by line' reading strategy and this made it difficult to scan-read through the text and to gain an overview of the documents. Reading text on the small screen was also slower than on paper, as this questionnaire respondent suggests:

The size of the text was relatively small for me. Plus the continual scrolling down put me off. I couldn't seem to be able to scroll as fast as I read and I kept losing my place as I did scroll. In the end it was too much of a stop start situation.

It could be that the act of scrolling through the text was not operationalized and instead required the focused, goal-directed effort of an action, as this interview comment suggests:

You're having to concentrate that little bit more because you're only seeing so many characters in vision at the same time. It's more a conscious effort to scroll down.

The disruption caused by the PDA, then, may have been due to the relative unfamiliarity of reading from a small screen and this meant that students could no longer employ the same strategies they used when reading from A4 size printed materials ('Only being able to see a small amount of text at any one time, you have to adopt a different reading strategy.'). Moreover, the limitations caused by the size and quality of the screen might not be easily overcome with practice. Some students, for example, said they experienced headaches and eyestrain when using the PDA for too long, suggesting that the poor screen quality is an important issue that may detract from the user experience.

\section{Navigation difficulties}

Closely related to the issue of small screen size was the problem of navigating through the documents, which some students found difficult on the PDA. The software's navigational tools, such as the 'Find' and 'Go to Paragraph' features, were considered 'irksome' and 'finicky'. It was also difficult to pick up on visual clues, such as headings, and some contextual clues, such as page numbers, were not available on the PDA: 'I found I got lost in the text as [there were] no visual cues to page number etc.' One interviewee suggested that more information about her location within the document space would have been beneficial:

I know it has a little bar on the side to say how you've progressed through the reading, 
but I'd still like something a little bit more . . . I've seen one somewhere on some computer screen that has percentages - how far you've got through the reading. I think something a little bit more obvious like that would be more helpful. I sort of like to know where I am in the reading.

Therefore, students had to learn to use new contextual clues to aid the process of navigation, and this caused some disruption to the reading activity. One student suggested that navigational difficulties might lessen over time: 'I found I could lose the sense of where I was quite easily with such a small screen but this was as much a question of practice as anything.' Some students also suggested that the documents on the PDA would have benefited from more extensive use of formatting in order to emulate printed materials, for example: 'There was no break in the text. Reading printed materials, the page is set out to show areas, categories, etc. Demarcation was not obvious.' It appears, then, that students would have liked to be able to use the familiar navigation strategies they had developed from past experience with printed text. However, features of the PDA, such as the small screen and scroll bar, meant these familiar strategies - or operations - could not be utilized, making it difficult to navigate through documents on the PDA.

\section{Note-taking}

Students also experienced difficulties when taking notes about the course materials on the PDA. The PDA introduced new methods for taking notes and as these methods were not yet operationalized, they were difficult and time-consuming to use. Typing on a full-size keyboard or writing on paper was deemed to be much faster and superior. Using the Graffiti handwriting system was slow and error-prone, as illustrated by this interview comment:

I experimented with the writing part ... and of course one of the problems was the letters weren't always coming out as I intended but I think that would have been a question of practice... So I got to the stage of being able to write and produce letters in print form on the screen but as it took a lot of time to do it I gave up.

However, there was recognition that the speed and accuracy of entering text may improve with practice. One interviewee who already owned a Palm PDA said: 'I have to say probably my previous experience with a Palm Pilot helped. I'm very, very aware of that [Graffiti] and have gotten much more skilful in it in the time I've had my Palm Pilot.' Over time, then, it is possible that the actions required to take notes on the PDA could become operationalized.

Despite the difficulties of entering text on the PDA, some students persevered and did use it for this purpose. For example, one interviewee described how the note-taking facility on the PDA opened up more possibilities for her to make use of time while away from her normal study environment:

It was nice to be able to take notes anywhere ... I usually take notes on a computer. If I lugged the course materials to the kids' band practice, or were to do that and handwrite the notes, then I'd have to go and I'd have to type them into the computer. But taking notes on the Palm, from that point of view, was wonderful.

Notes recorded on the Palm were already in electronic format and could be easily transferred to the desktop computer. This allowed the student to devise strategies for 
overcoming limitations imposed by note-taking methods on the PDA: 'the key thing was to get the notes down. If the odd character was wrong it was more time-consuming to go back and correct it than it would be just to sort it out when you've got it on the main machine.' One benefit of using the PDA for this purpose, then, is that it can be used in conjunction with other tools, in particular the desktop or laptop computer.

\section{Use of existing tools}

The PDA did not replace the tools students already used to support reading. Instead, it was used in conjunction with existing tools, and - for students who used the PDA extensively - it modified the way those tools were used. Having course materials on the PDA complemented the printed documents: 'Having the choice - between paper and Palm - meant that I felt like I could process more of the course materials, and consolidate my understanding of it; reading in one domain reinforced reading in the other domain.' Students could use the PDA to read or revise the materials while on the move and revert to using the printed documents when in their normal study environment. Therefore, the PDA became an extension of the printed materials, providing more opportunities for students to read and review the course materials.

The PDA could also be used in conjunction with the desktop computer. One questionnaire respondent used the PDA to 'cut and paste important points/quotes' from the course materials and then 'HotSynced' this to her PC. This meant that notes recorded on the PDA could be incorporated into more extensive documents on the PC. For some students, the PDA reduced reliance upon other tools. One student commented: 'Now I use it on the move instead of pen and paper.' Another said she uses the PDA to support the initial stages of essay-writing. The advantages of the new tool being instantly available highlighted limitations of other tools:

Great for initial essay-writing (getting ideas jotted down as they are thought of, rather than trying to get to a computer, where you have forgotten by the time you've turned it on. Or even to paper sometimes when you've forgotten your thought by the time you have found a working biro...).

Introducing a new tool into an activity, then, has the potential to change the way existing tools are used. In this context, the PDA provided an extension of existing tools, such as the printed study guide and the desktop computer. In some cases, as in the example above, the PDA could also be used to overcome limitations of existing tools.

\section{Discussion}

These findings suggest that the introduction of a new mediating tool - a PDA - does modify the activity of reading course materials in a distance education context. The new tool presents new possibilities and constraints; as Carroll et al. (1991) argued, these have the potential to change dramatically the activity the tool is used to support. In activity theory terms, these changes may affect both the social context of activity and the distinction between the actions and operations that make up the activity (Kuutti, 1996). In this study the changes are most apparent at the action/operation level. The new tool introduced new ways of doing things - new methods of entering text, new requirements for navigation and a new display size for the text - and this meant students could not apply the operations they had developed from past experience of using paper documents and 
desktop computers. This had the effect of disrupting the reading activity, making it slower and more difficult than reading on paper. These findings, therefore, are similar to earlier studies comparing paper-based reading with onscreen reading (Dillon, 1994; O'Hara and Sellen, 1997): existing tools, with which the user is familiar, are viewed more favourably than new tools, which disrupt the activity. Using the PDA was different from using both paper materials and desktop or laptop computers. The screen size was the most notable difference as this severely limited the amount of text on display at a time. Therefore, scrolling through the text was a necessary, but somewhat arduous, process. Furthermore, data manipulation techniques on the PDA were different from familiar techniques used with both paper and desktop computers - for example, flicking through paper documents, using a pen to record notes, or using a mouse and keyboard on a desktop computer. Therefore, in general, students found it difficult to record notes on the PDA or to interact with the text in the same way as they would when using more familiar tools.

For some students, however, the benefits of using the PDA were great. The tool was considered more lightweight and portable than the 'cumbersome' A4-size printed materials. This meant the course materials could be carried around and used 'anytime

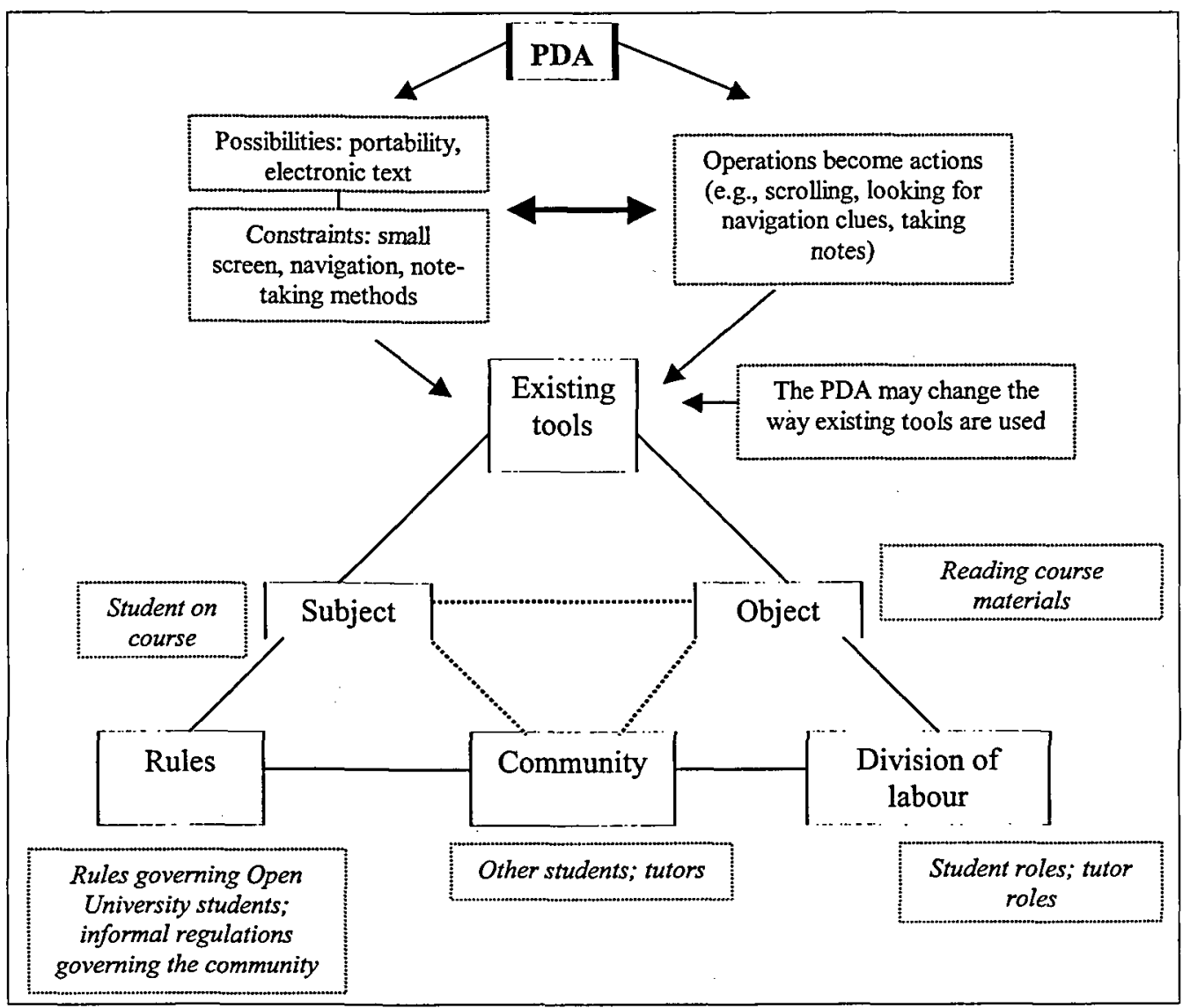

Figure 3: The introduction of a new tool (PDA) on the activity of reading course materials 
anywhere' which had the effect of modifying the wider context of the activity: with the PDA, the activity of reading course materials could be structured more effectively around other activities in which the student was involved. In addition, the PDA had the potential to change the way students used existing tools. Some students who used the PDA for notetaking, for example, found they no longer used pen and paper, and they were able to use the PDA in conjunction with the desktop computer to extend and modify their notes.

Figure 3 extends the activity system model developed by Engestrom (1996) to represent the effect that the PDA had upon the activity of reading course materials. The new tool is shown to introduce new possibilities and constraints, which interact with, and change, the actions and operations of the activity. Thus, most of the effects of the new tool can be seen at the top of the model, whereas Engestrom's wider social context of activity (the community, rules and division of labour) remain unchanged. This may be because the activity in question is an individual activity. Although students are members of a community - consisting of other students and tutors - and they take part in community activities such as online conferencing during other parts of the course, the activity of reading course materials is primarily carried out alone. The notions of community, rules and division of labour, therefore, would be more useful for research examining activities that are specifically collaborative in nature (for example, Mwanza, 2001). However, Halloran et al. (2002) did examine a collaborative learning situation and they found that 'rules' and 'division of labour' were not useful constructs in the context of their research.

One limitation of the model for illustrating the findings from this study is that it does not allow a representation of the multiple activities in which a subject is involved. This means that the effect of the portability of the PDA - which changed the way the activity of reading was structured around othef activities - cannot be represented. There is insufficient scope in this paper to provide a solution to this limitation. Nevertheless, it is an issue that could be elaborated in further research using activity theory to examine the effect of new technologies.

\section{Conclusion}

The study showed that students had mixed responses to the use of PDAs for reading course materials. The PDA disrupted and constrained the reading activity through its introduction of new conditions, which made it difficult for students to apply the operations they had developed from experience using paper and desktop computers; instead they had to formulate new time-intensive actions. Limitations such as the small screen size, navigational difficulties and unfamiliar note-taking methods changed the way students read course materials. They had to adopt a concentrated, line-by-line reading strategy, and were unable to skim-read or move backwards and forwards within the documents as easily as they could with paper. However, the ability to have 'anytime, anywhere' access to the course materials was welcomed by students. In this respect the PDA was a valuable tool, suggesting that the provision of course materials for access on a portable device is useful for distance education students. However, for some students the constraints of using the PDA, in particular the small screen size, meant they were reluctant to use it instead of paper. While it would be premature to consider replacing printed documents, then, this study does show that there may be some value in using PDAs to extend existing tools. 


\section{Acknowledgements}

This study forms part of my Ph.D. research, supervised by Professor Eileen Scanlon and Dr Ann Jones. The project was conducted in collaboration with Dr Agnes KukulskaHulme, chair of the course team that runs the Open University course 'Applications of Information Technology in Open and Distance Education'.

\section{References}

Bodker, S. (1991), Through the Interface: A Human Activity Approach to User Interface Design, Hillsdale, NJ: Lawrence Erlbaum Associates.

Carroll, J. M., Kellogg, W. A. and Rosson, M. B. (1991), 'The task-artifact cycle', in J. M. Carroll (ed.), Designing Interaction: Psychology at the Human-Computer Interface, Cambridge: Cambridge University Press.

Dillon, A. (1994), Designing Usable Electronic Text: Ergonomic Aspects of Human Information Usage, London: Taylor \& Francis.

Engestrom, Y. (1996), 'Toward overcoming the encapsulation of school learning', in H. Daniels (ed.), An Introduction to Vygotsky, London and New York: Routledge.

Fung, P., Hennessy, S. and O'Shea, T. (1998), 'Pocketbook computing: a paradigm shift?', Computers in the Schools, 14 (3/4), 109-18.

Halloran, J., Rogers, Y. and Scaife, M. (2002), "Taking the "no" out of Lotus Notes: activity theory, groupware, and student groupwork', in G. Stahl (ed.), Computer Support for Collaborative Learning: Foundations for a CSCL Community - Proceedings of CSCL 2002 (Boulder, Colorado, USA January 7-11), Hillsdale, NJ: Lawrence Erlbaum Associates.

Hennessy, S. (2000), 'Graphing investigations using portable (palmtop) technology', Journal of Computer Assisted Learning, 16, 243-58.

Jones, A., Kirkup, G. and Kirkwood, A. (1992), Personal Computers for Distance Education: The Study of an Educational Innovation, London: Paul Chapman Publishing.

Kuutti, K. (1996), 'Activity theory as a potential framework for human-computer interaction research', in B. A. Nardi (ed.), Context and Consciousness: Activity Theory and Human-Computer Interaction, Cambridge, MA and London: MIT Press.

Leont'ev, A. N. (1978), Activity, Consciousness, and Personality, Englewood Cliffs: Prentice Hall.

Leont'ev, A. N. (1979), 'The problem of activity in psychology', in J. V. Wertsch (ed.), The Concept of Activity in Soviet Psychology, Armonk, NY: M. E. Sharpe, Inc.

Mwanza, D. (2001), Changing Tools, Changing Attitudes: Effects of Introducing a CSCL System to Promote Learning at Work, Milton Keynes: Knowledge Media Institute, Open University.

O'Hara, K. and Sellen, A. (1997), 'A comparison of reading paper and on-line documents', Proceedings of CHI 97, Atlanta, GA: ACM. 
Pascoe, J., Ryan, N. and Morse, D. (2000), 'Using while moving: HCI issues in fieldwork environments', ACM Transactions on Computer-Human Interaction, 7 (3), 417-37.

Sharples, M. (2000), 'The design of personal mobile technologies for lifelong learning', Computers and Education, 34 (3-4), 177-93.

Soloway, E., Norris, C., Blumenfeld, P., Fishman, B., Krajcik, J. and Marx, R. (2001), 'Log on education: handheld devices are ready-at-hand', Communications of the $A C M, 44$ (6), 15-20.

Stonier, T. (1991), 'Futures: the personal electronic pocket-book', Educational and Training Technology International, 28 (4), 364-8.

Vygotsky, L. S. (1978), Mind in Society: The Development of Higher Psychological Processes, Cambridge, MA and London: Harvard University Press.

Waycott, J. and Kukulska-Hulme, A. (2001), An Evaluation of the Use of Personal Digital Assistants for Reading Course Materials on H802: Final Report, Milton Keynes: Institute of Educational Technology, Open University. 